\title{
A Two-Country Discontinuous General Equilibrium Model
}

\author{
Ciprian Necula \\ DOFIN \\ Academy of Economic Studies \\ Bucharest, Romania \\ email: ciprian.necula@fin.ase.ro
}

First draft: July 52008

\begin{abstract}
The aim of this paper is to develop a continuous time general equilibrium model for a two country Lucas type economy. The model assumes that the output in the two countries follows a jump-diffusion stochastic process. We obtain the results concerning the evaluation of financial assets, the determination of the exchange rate, of the interest rate, and of the risk premium in this two-country economy.
\end{abstract}

Keywords: general equilibrium model, two-country Lucas economy, exchange rate, risk premium, jump-diffusion.

JEL Classification: C02, C61, D50, G12

Acknowledgements: I would like to thank Professor Moisă Altăr for continuous support. 


\section{INTRODUCTION}

The theory of general equilibrium models established powerful results regarding asset pricing by relating interest rates and asset risk premium to underlying economic variables.

Merton (1973) developed an intertemporal capital asset pricing model deriving the relationship among the equilibrium expected rates of return on assets. He shows that when investment opportunities are changing stochastically over time the relationship includes effects which have no analogue in the classical one period CAPM.

Lucas (1978) considers an economy with homogeneous individuals and a single consumption good. The random output is exogenously given. Assets are defined as claims to all or a part of the output. The equilibrium asset prices are determined as a function of the physical state of the economy by solving a functional equation that is a generalization of the Martingale property of stochastic price sequences.

In the consumption-based CAPM of Breeden (1979), the asset risk premium it is determined by the representative agent risk aversion and by the covariance between consumption and asset prices.

Lucas (1982) investigates the determination of prices, interest rates and currency exchange rates in an infinitely-lived two-country economy. The main assumption of the model is the perfect-pooling equilibrium (i.e. since agents are risk averse and since they have identical preferences, an equilibrium in which all agents hold the same portfolio will be indefinitely maintained) Bakshi and Chen (1997) extended the model in continuous time.

The economic structure of the model developed Cox, Ingersoll and Ross (1985) differs from Lucas (1978) in that the production is endogenously determined. The model is fully consistent with maximizing behavior of the economic agents. The model endogenously determines the relationship between the stochastic process followed by the equilibrium price of any financial asset and the underlying real variables.

In most general equilibrium models money often plays no role and all prices are denominated in units of the consumption good. Bakshi and Chen (1996) provide a way of integrating asset pricing theory with models from monetary economics. According to this model both production risk and monetary risk matter for the purpose of asset valuation. The expected risk premium on a risky asset is linear in its covariance with both production risk and monetary risk.

In this paper we develop a new continuous time general equilibrium model for a two country Lucas type economy. The model assumes that the output in the two countries follows a jump-diffusion stochastic process. We obtain the results concerning the determination of the exchange rate, of the interest rate, and of the risk premium. 
This paper is organized as follows: in the second section we present the model hypotheses and obtain some basic results regarding asset pricing and the interest rates. In the third section we derive the relationship between the risk premium and the underlying macroeconomic variables. In the fourth section we study the dynamics of the exchange rate. The final section concludes.

\section{THE MODEL}

Consider a two-country Lucas type economy (Lucas 1978; Lucas 1982). The Home GDP equals $2 y_{t}$ where $y_{t}$ follows a dynamical equation consisting of a continuous part $\left(\frac{d y_{t}}{y_{t}}\right)_{c}$ given by a diffusion process driven by a Brownian Motion and a discontinuous part modeled using a compound Poisson process quantifying the jumps due to rare events. Hence, the GDP follows a jump-diffusion:

$$
\frac{d y_{t}}{y_{t}}=\left(\frac{d y_{t}}{y_{t}}\right)_{c}+J d N_{t}
$$

where the density function of the amplitude of the jumps $J$ is given by $\varphi_{J}$ , and $N_{t}$ is a Poisson process with intensity $\lambda$ (independent of $W_{t}$ ):

$$
P\left(N_{t}=n\right)=p(n)=\frac{e^{-\lambda t}(\lambda t)^{n}}{n !}
$$

Similarly, the Foreign GDP dynamics (the Foreign variables are denoted with ${ }^{*}$ ) is given by:

$$
\frac{d y_{t}^{*}}{y_{t}^{*}}=\left(\frac{d y_{t}^{*}}{y_{t}^{*}}\right)_{c}+J^{*} d N_{t}^{*}
$$

where $N_{t}^{*}$ is a Poisson process with intensity $\lambda^{*} . N_{t}$ and $N_{t}^{*}$ are not correlated.

Regarding the money supply $\left(M_{t}=2 m_{t}, M_{t}^{*}=2 m_{t}^{*}\right)$ the model assumes a dynamics given by a diffusion process generated by a Brownian Motion that can be correlated with the Brownian Motion influencing the GDP. Hence, there are no jumps in the evolution of the money supply: 


$$
\frac{d m_{t}}{m_{t}}=\left(\frac{d m_{t}}{m_{t}}\right)_{c}
$$

Both Home and Foreign representative economic agents have the same utility function:

$$
U\left(c, c^{*}\right)=u(c)+\bar{u}\left(c^{*}\right)
$$

The model assumes that in each country there is only one equity share (i.e. a stock index), initially held by the country's representative agent, paying dividends given by $2 y_{t} P_{t}$, where $P_{t}$ is the Home price level. There are also traded zero-netsupply securities. The goods produced in each country can be purchased only in the producing country's currency. Goods and capital are perfectly mobile.

The optimization problem of the Home representative agent is given by:

$$
\max _{c, c^{*}, \alpha, \alpha^{*}, \beta} E_{t} \int_{t}^{\infty} \exp \{-\phi(s-t)\} U\left(c_{s}, c_{s}^{*}\right) d s
$$

where $\phi$ is the time preference parameter, $\alpha, \alpha^{*}$ the number of Home, respectively Foreign stocks held in the portfolio, and $\beta$ is the number of units held from a financial asset paying $\delta_{t}$ units of the domestic good and $\delta_{t}^{*}$ units of the foreign good.

Proposition 1. In equilibrium we have that:

a) the commodity price level at time $t$ is:

$$
P_{t}=\frac{m_{t}}{y_{t}}, P_{t}^{*}=\frac{m_{t}^{*}}{y_{t}^{*}}
$$

b) the nominal exchange rate at time $t$ is:

$$
e_{t}=\frac{y_{t}^{*} \bar{u}^{\prime}\left(y_{t}^{*}\right)}{y_{t} u^{\prime}\left(y_{t}\right)} \frac{m_{t}^{*}}{m_{t}}
$$

c) the real exchange rate at time $t$ is:

$$
\varepsilon_{t}=\frac{\bar{u}^{\prime}\left(y_{t}^{*}\right)}{u^{\prime}\left(y_{t}\right)}
$$

d) the real price of the Home equity share is:

$$
s_{t}=E_{t} \int_{t}^{\infty} \exp \{-\phi(\tau-t)\} \frac{u^{\prime}\left(y_{\tau}\right)}{u^{\prime}\left(y_{t}\right)} 2 y_{\tau} d \tau
$$

e) the real price of the Foreign equity share is: 


$$
s_{t}^{*}=E_{t} \int_{t}^{\infty} \exp \{-\phi(\tau-t)\} \frac{\bar{u}^{\prime}\left(y_{\tau}^{*}\right)}{\bar{u}^{\prime}\left(y_{t}^{*}\right)} 2 y_{\tau}^{*} d \tau
$$

f) the real price (in Home goods) of a financial asset is:

$$
q_{t}=E_{t} \int_{t}^{\infty} \exp \{-\phi(\tau-t)\} \frac{u^{\prime}\left(y_{\tau}\right)}{u^{\prime}\left(y_{t}\right)}\left[\delta_{\tau}+\varepsilon_{\tau} \delta_{\tau}^{*}\right] d \tau
$$

\section{Proof:}

The methodology used to proof the results consists in solving a discrete time dynamic programming problem, by dividing the time horizon into discrete time interval of length $d t$ and then in obtaining the continuous time limit (Bakshi and Chen 1996; Grossman and Shiller 1982).

The wealth of the Home representative agent denominated in Home currency is given by:

$$
W_{t}=P_{t} c_{t}+e_{t} P_{t}^{*} c_{t}^{*}+\alpha_{t} S_{t}+\alpha_{t}^{*} e_{t} S_{t}^{*}+\beta_{t} Q_{t}
$$

where $S_{t}$ is the nominal price of the Home equity, $S_{t}^{*}$ the nominal price of the Foreign equity (in Foreign currency), and $Q_{t}$ is the nominal price of a financial asset paying $\delta_{t}$ units of the domestic good and $\delta_{t}^{*}$ units of the foreign good.

In order to buy goods the Home representative agent has $n_{t}$ units of the Home currency and $n_{t}^{*}$ units of the Foreign currency:

$$
\begin{aligned}
& P_{t} c_{t} \leq n_{t} \\
& P_{t}^{*} c_{t}^{*} \leq n_{t}^{*}
\end{aligned}
$$

Her wealth at time $t+d t$ is:

$$
\begin{aligned}
W_{t+d t}= & {\left[n_{t}-P_{t} c_{t}+e_{t+d t}\left(n_{t}^{*}-P_{t}^{*} c_{t}^{*}\right)\right]+} \\
& +\alpha_{t}\left(S_{t+d t}+P_{t+d t} 2 y_{t} d t\right)+\alpha_{t}^{*} e_{t+d t}\left(S_{t+d t}^{*}+P_{t+d t}^{*} 2 y_{t}^{*} d t\right)+ \\
& +\beta_{t}\left[Q_{t+d t}+P_{t+d t} \delta_{t} d t+e_{t+d t} P_{t+d t}^{*} \delta_{t}^{*} d t\right]+ \\
& +\left(M_{t+d t}-M_{t}\right)
\end{aligned}
$$

Denoting by $V(\cdot)$ the value function and with $\lambda_{t}$ the Lagrange multiplier, the FOC are given by: 


$$
\begin{gathered}
\frac{\partial U}{\partial c}\left(c, c^{*}\right)=u^{\prime}\left(c_{t}\right)=\lambda_{t} P_{t} \\
\frac{\partial U}{\partial c^{*}}\left(c, c^{*}\right)=\bar{u}^{\prime}\left(c_{t}^{*}\right)=\lambda_{t} e_{t} P_{t}^{*} \\
\left.\lambda_{t} S_{t}=\exp (-\phi d t) E_{t} \mid V^{\prime}\left(W_{t+d t}\right)\left(S_{t+d t}+P_{t+d t} Y_{t} d t\right)\right] \\
\left.\lambda_{t} e_{t} S_{t}^{*}=\exp (-\phi d t) E_{t} \mid V^{\prime}\left(W_{t+d t}\right) e_{t+d t}\left(S_{t+d t}^{*}+P_{t+d t}^{*} Y_{t}^{*} d t\right)\right] \\
\lambda_{t} Q_{t}=\exp (-\phi d t) E_{t}\left\{V^{\prime}\left(W_{t+d t}\right)\left[\left(S_{t+d t}+P_{t+d t} \delta_{t} d t\right)+e_{t+d t}\left(S_{t+d t}^{*}+P_{t+d t}^{*} \delta_{t}^{*} d t\right)\right]\right\}
\end{gathered}
$$

Using the envelope theorem one has that:

$$
\lambda_{t}=V^{\prime}\left(W_{t}\right)
$$

The fact that there are financial assets with positive returns (risk free bonds) implies that the constraint (14) is binding:

$$
\begin{aligned}
& P_{t} c_{t}=n_{t} \\
& P_{t}^{*} c_{t}^{*}=n_{t}^{*}
\end{aligned}
$$

Since we assumes a Lucas type economy (Lucas 1982) a perfect-pooling equilibrium is conjectured:

$$
\begin{aligned}
& c_{t}=y_{t}, c_{t}^{*}=y_{t}^{*} \\
& \alpha_{t}=\frac{1}{2}, \alpha_{t}^{*}=\frac{1}{2}, \beta_{t}=0
\end{aligned}
$$

Using (22) and the similar equalities written for the Foreign representative agent one obtain the commodity price level (equation (7)).

Using (16), (17) and (23) the nominal exchange rate is:

$$
e_{t}=\frac{\bar{u}^{\prime}\left(y_{t}^{*}\right)}{u^{\prime}\left(y_{t}\right)} \frac{P_{t}}{P_{t}^{*}}
$$

Using (21), the equations (18), (19) and (20) can be rewritten as: 


$$
\begin{aligned}
& u^{\prime}\left(y_{t}\right) \frac{S_{t}}{P_{t}}=\exp (-\phi d t) E_{t}\left[u^{\prime}\left(y_{t+d t}\right)\left(\frac{S_{t+d t}}{P_{t+d t}}+2 y_{t} d t\right)\right] \\
& \bar{u}^{\prime}\left(y_{t}^{*}\right) \frac{S_{t}}{P_{t}}=\exp (-\phi d t) E_{t}\left[\bar{u}^{\prime}\left(y_{t+d t}^{*}\right)\left(\frac{S_{t+d t}^{*}}{P_{t+d t}^{*}}+2 y_{t}^{*} d t\right)\right]
\end{aligned}
$$

respectively

$$
u^{\prime}\left(y_{t}\right) \frac{Q_{t}}{P_{t}}=\exp (-\phi d t) E_{t}\left[u^{\prime}\left(y_{t+d t}\right)\left(\frac{Q_{t+d t}}{P_{t+d t}}+\delta_{t} d t+\varepsilon_{t+d t} \delta_{t}^{*} d t\right)\right]
$$

By solving forward the equations (25), (26) and (27), and by obtaining the continuous limit one gets (10), (11), and (20).

Corollary 1. In equilibrium we have that:

a) the nominal price of the Home equity at time $t$ is:

$$
S_{t}=E_{t} \int_{t}^{\infty} \exp \{-\phi(\tau-t)\} \frac{y_{\tau} u^{\prime}\left(y_{\tau}\right)}{y_{t} u^{\prime}\left(y_{t}\right)} \frac{m_{t}}{m_{\tau}} 2 P_{\tau} y_{\tau} d \tau
$$

b) the nominal price of the Foreign equity at time $t$ is:

$$
S_{t}^{*}=E_{t} \int_{t}^{\infty} \exp \{-\phi(\tau-t)\} \frac{y_{\tau}^{*} u^{\prime}\left(y_{\tau}^{*}\right)}{y_{t}^{*} u^{\prime}\left(y_{t}^{*}\right)} \frac{m_{t}^{*}}{m_{\tau}^{*}} 2 P_{\tau}^{*} y_{\tau}^{*} d \tau
$$

c) the nominal price of a financial asset paying $\delta_{t}$ units of the domestic good and $\delta_{t}^{*}$ units of the foreign good:

$Q_{t}=E_{t} \int_{t}^{\infty} \exp \{-\phi(\tau-t)\} \frac{y_{\tau} u^{\prime}\left(y_{\tau}\right)}{y_{t} u^{\prime}\left(y_{t}\right)} \frac{m_{t}}{m_{\tau}}\left[P_{\tau} \delta_{\tau}+e_{\tau} P_{\tau}^{*} \delta_{\tau}^{*}\right] d \tau$

d) the nominal price of a financial asset with only one cash-flow, $\Pi_{T}=f\left(y_{T}, y_{T}^{*}, e_{T}, P_{T}, P_{T}^{*}\right)$, is:

$$
Q(t, T)=\exp \{-\phi(T-t)\} E_{t}\left[\frac{y_{\tau} u^{\prime}\left(y_{\tau}\right)}{y_{t} u^{\prime}\left(y_{t}\right)} \frac{m_{t}}{m_{\tau}} \Pi_{T}\right]
$$

e) the real price of a real zero-coupon bond with maturity $T$ is:

$$
b(t, T)=\exp \{-\phi(T-t)\} E_{t}\left[\frac{u^{\prime}\left(y_{T}\right)}{u^{\prime}\left(y_{t}\right)}\right]
$$

f) the nominal price of a nominal zero-coupon bond with maturity $T$ is: 


$$
B(t, T)=\exp \{-\phi(T-t)\} E_{t}\left[\frac{y_{T} u^{\prime}\left(y_{T}\right)}{y_{t} u^{\prime}\left(y_{t}\right)} \frac{m_{T}}{m_{t}}\right]
$$

Proof:

The results are a straightforward application of Proposition 1.

q.e.d.

Proposition 2. In equilibrium we have that:

a) the real interest rate is:

$$
\begin{array}{r}
r_{t}=\phi-\frac{y_{t} u^{\prime \prime}\left(y_{t}\right)}{u^{\prime}\left(y_{t}\right)} \frac{1}{d t} E_{t}\left(\frac{d y_{t}}{y_{t}}\right)_{c}-\frac{1}{2} \frac{y_{t}^{2} u^{\prime \prime \prime}\left(y_{t}\right)}{u^{\prime}\left(y_{t}\right)} \frac{1}{d t} E_{t}\left(\frac{d y_{t}}{y_{t}}\right)_{c}^{2} \\
-\lambda \int_{\mathbf{R}} \frac{u^{\prime}\left(y_{t}(1+x)\right)-u^{\prime}\left(y_{t}\right)}{u^{\prime}\left(y_{t}\right)} \varphi_{J}(x) d x
\end{array}
$$

b) the nominal interest rate is:

$$
\begin{aligned}
& R_{t}=\phi-\left[1+\frac{y_{t} u^{\prime \prime}\left(y_{t}\right)}{u^{\prime}\left(y_{t}\right)}\right] \frac{1}{d t} E_{t}\left(\frac{d y_{t}}{y_{t}}\right)_{c}-\left[\frac{y_{t} u^{\prime \prime}\left(y_{t}\right)}{u^{\prime}\left(y_{t}\right)}+\frac{1}{2} \frac{y_{t}^{2} u^{\prime \prime \prime}\left(y_{t}\right)}{u^{\prime}\left(y_{t}\right)}\right] \frac{1}{d t} E_{t}\left(\frac{d y_{t}}{y_{t}}\right)_{c}^{2} \\
&+\frac{1}{d t} E_{t}\left(\frac{d m_{t}}{m_{t}}\right)-\frac{1}{d t} E_{t}\left(\frac{d m_{t}}{m_{t}}\right)^{2}+\left[1+\frac{y_{t} u^{\prime \prime}\left(y_{t}\right)}{u^{\prime}\left(y_{t}\right)}\right] \frac{1}{d t} E_{t}\left(\frac{d y_{t}}{y_{t}}\right)\left(\frac{d m_{t}}{m_{t}}\right)^{\prime} \\
&-\lambda \int_{\mathbf{R}} \frac{u^{\prime}\left(y_{t}(1+x)\right)(1+x)-u^{\prime}\left(y_{t}\right)}{u^{\prime}\left(y_{t}\right)} \varphi_{J}(x) d x
\end{aligned}
$$

\section{Proof:}

The relation between the real interest rate and the price of the real zerocoupon bond is:

$$
r_{t} d t=b(t, t+d t)^{-1}-1
$$

Using the approximation $\exp (\phi d t) \approx 1+\phi d t$, equation (32) can be written as:

$$
1+\phi d t=E_{t}\left[\frac{u^{\prime}\left(y_{t+d t}\right)}{u^{\prime}\left(y_{t}\right)}\left(1+r_{t} d t\right)\right]
$$

By applying the Ito Lemma for Levy processes to the function $u^{\prime}(y)$ one has that: 


$$
d u^{\prime}\left(y_{t}\right)=y_{t} u^{\prime \prime}\left(y_{t}\right)\left(\frac{d y_{t}}{y_{t}}\right)_{c}+\frac{1}{2} y_{t}^{2} u^{\prime \prime \prime}\left(y_{t}\right)\left(\frac{d y_{t}}{y_{t}}\right)_{c}^{2}+\left[u^{\prime}\left(y_{t}(1+J)\right)-u^{\prime}\left(y_{t}\right)\right] d N_{t}
$$

It follows that:

$$
\frac{u^{\prime}\left(y_{t+d t}\right)}{u^{\prime}\left(y_{t}\right)}=1+\frac{y_{t} u^{\prime \prime}\left(y_{t}\right)}{u^{\prime}\left(y_{t}\right)}\left(\frac{d y_{t}}{y_{t}}\right)_{c}+\frac{1}{2} \frac{y_{t}^{2} u^{\prime \prime \prime}\left(y_{t}\right)}{u^{\prime}\left(y_{t}\right)}\left(\frac{d y_{t}}{y_{t}}\right)_{c}^{2}+\left[\frac{u^{\prime}\left(y_{t}(1+J)\right)-u^{\prime}\left(y_{t}\right)}{u^{\prime}\left(y_{t}\right)}\right] d N_{t}
$$

Using some the stochastic calculus for Levy processes, respectively

$$
\left(\frac{d y_{t}}{y_{t}}\right)_{c} d t=0,\left(\frac{d y_{t}}{y_{t}}\right)_{c}^{2} d t=0, d N_{t} d t=0
$$

one obtains equation (34).

The relation between the nominal interest rate and the price of the nominal zero-coupon bond is:

$$
R_{t} d t=B(t, t+d t)^{-1}-1
$$

Equation (33) can be rewritten as:

$$
1+\phi d t=E_{t}\left[\frac{y_{t+d t} u^{\prime}\left(y_{t+d t}\right)}{y_{t} u^{\prime}\left(y_{t}\right)} \frac{m_{t}}{m_{t+d t}}\left(1+R_{t} d t\right)\right]
$$

By applying the Ito Lemma for Levy processes to the function $y u^{\prime}(y)$ one has that:

$$
\begin{aligned}
\frac{y_{t+d t} u^{\prime}\left(y_{t+d t}\right)}{y_{t} u^{\prime}\left(y_{t}\right)}=1 & +\left[1+\frac{y_{t} u^{\prime \prime}\left(y_{t}\right)}{u^{\prime}\left(y_{t}\right)}\right]\left(\frac{d y_{t}}{y_{t}}\right)_{c}+\left[\frac{y_{t} u^{\prime \prime}\left(y_{t}\right)}{u^{\prime}\left(y_{t}\right)}+\frac{1}{2} \frac{y_{t}^{2} u^{\prime \prime \prime}\left(y_{t}\right)}{u^{\prime}\left(y_{t}\right)}\right]\left(\frac{d y_{t}}{y_{t}}\right)_{c}^{2} \\
& +\left[\frac{u^{\prime}\left(y_{t}(1+J)\right)(1+J)-u^{\prime}\left(y_{t}\right)}{u^{\prime}\left(y_{t}\right)}\right] d N_{t}
\end{aligned}
$$

Using the classical Ito Lemma it follows that: 


$$
\frac{m_{t}}{m_{t+d t}}=1-\frac{d m_{t}}{m_{t}}+\left(\frac{d m_{t}}{m_{t}}\right)^{2}
$$

Using the stochastic calculus results in (40) one obtains the equation (35).

q.e.d.

\section{THE RISK PREMIUM}

The dynamical equations of the real price $(q)$ and of the nominal price ( $Q$ ) for a financial asset paying $\delta_{t}$ units of the domestic good and $\delta_{t}^{*}$ units of the foreign good consists of a continuous part, as well as a discontinuous part quantifying the jumps due to shocks in the two countries:

$$
\begin{gathered}
\frac{d q_{t}}{q_{t}}=\left(\frac{d q_{t}}{q_{t}}\right)_{c}+J_{q} d N_{t}+J_{q}^{*} d N_{t}^{*} \\
\frac{d Q_{t}}{Q_{t}}=\left(\frac{d Q_{t}}{Q_{t}}\right)_{c}+J_{Q} d N_{t}+J_{Q}^{*} d N_{t}^{*}
\end{gathered}
$$

The expected real return is given by:

$$
\mu_{q}=\frac{1}{d t} E_{t}\left(\frac{d q_{t}+\delta_{t} d t+\varepsilon_{t} \delta_{t}^{*} d t}{q_{t}}\right)
$$

and the nominal one by:

$$
\mu_{Q}=\frac{1}{d t} E_{t}\left(\frac{d Q_{t}+P_{t} \delta_{t} d t+e_{t} P_{t}^{*} \delta_{t}^{*} d t}{Q_{t}}\right)
$$

Proposition 3. In equilibrium we have that:

a) the real risk premium is given by:

$$
\mu_{q}-r_{t}=-\frac{y_{t} u^{\prime \prime}\left(y_{t}\right)}{u^{\prime}\left(y_{t}\right)} \frac{1}{d t} E_{t}\left(\frac{d y_{t}}{y_{t}}\right)_{c}\left(\frac{d q_{t}}{q_{t}}\right)_{c}-\lambda E\left[J_{q} \frac{u^{\prime}\left(y_{t}(1+J)\right)-u^{\prime}\left(y_{t}\right)}{u^{\prime}\left(y_{t}\right)}\right]
$$

b) the nominal risk premium is given by: 


$$
\begin{array}{r}
\mu_{Q}-R_{t}=-\left[1+\frac{y_{t} u^{\prime \prime}\left(y_{t}\right)}{u^{\prime}\left(y_{t}\right)}\right] \frac{1}{d t} E_{t}\left(\frac{d y_{t}}{y_{t}}\right)_{c}\left(\frac{d Q_{t}}{Q_{t}}\right)_{c}+\frac{1}{d t} E_{t}\left(\frac{d m_{t}}{m_{t}}\right)_{c}\left(\frac{d Q_{t}}{Q_{t}}\right)_{c} \\
-\lambda E\left[J_{Q} \frac{u^{\prime}\left(y_{t}(1+J)\right)(1+J)-u^{\prime}\left(y_{t}\right)}{u^{\prime}\left(y_{t}\right)}\right]
\end{array}
$$

\section{Proof:}

From (27), (32) and (36) one has that:

$$
E_{t}\left[\frac{u^{\prime}\left(y_{t+d t}\right)}{u^{\prime}\left(y_{t}\right)}\left(\frac{d q_{t}+\delta_{t} d t+\varepsilon_{t} \delta_{t}^{*} d t}{q_{t}}-r_{t} d t\right)\right]=0
$$

Using (39), and the following stochastic calculus results

$$
\left(\frac{d y_{t}}{y_{t}}\right)_{c} d N_{t}=0,\left(\frac{d y_{t}}{y_{t}}\right)_{c} d N_{t}^{*}=0, d N_{t} d N_{t}^{*}=0, d N_{t}^{2}=d N_{t}
$$

one obtains the equation (49).

From (27), (33) and (41) it follows that:

$$
E_{t}\left[\frac{y_{t+d t} u^{\prime}\left(y_{t+d t}\right)}{y_{t} u^{\prime}\left(y_{t}\right)} \frac{m_{t}}{m_{t+d t}}\left(\frac{d Q_{t}+P_{t} \delta_{t} d t+e_{t} P_{t}^{*} \delta_{t}^{*} d t}{Q_{t}}-R_{t} d t\right)\right]=0
$$

Equation (50) can be obtained using (43) şi (44).

\section{THE EXCHENGE RATE DYNAMICS}

The dynamics for the real $(\varepsilon)$ and the nominal $(e)$ exchange rate is:

$$
\frac{d \varepsilon_{t}}{\varepsilon_{t}}=\left(\frac{d \varepsilon_{t}}{\varepsilon_{t}}\right)_{c}+J_{\varepsilon} d N_{t}+J_{\varepsilon}^{*} d N_{t}^{*}
$$

and respectively

$$
\frac{d e_{t}}{e_{t}}=\left(\frac{d e_{t}}{e_{t}}\right)_{c}+J_{e} d N_{t}+J_{e}^{*} d N_{t}^{*}
$$

The real and nominal expected depreciation is given by: 


$$
\mu_{\varepsilon}=\frac{1}{d t} E_{t}\left(\frac{d \varepsilon_{t}}{\varepsilon_{t}}\right), \mu_{e}=\frac{1}{d t} E_{t}\left(\frac{d e_{t}}{e_{t}}\right)
$$

Proposition 4. In equilibrium we have that:

a) the jump amplitude of the real exchange rate is:

$$
J_{\varepsilon}=\frac{u^{\prime}\left(y_{t}\right)}{u^{\prime}\left(y_{t}(1+J)\right)}-1, \quad J_{\varepsilon}^{*}=\frac{\bar{u}^{\prime}\left(y_{t}^{*}\left(1+J^{*}\right)\right)}{\bar{u}^{\prime}\left(y_{t}^{*}\right)}-1
$$

b) the real expected depreciation is:

$$
\begin{array}{r}
\mu_{\varepsilon}-\left(r_{t}-r_{t}^{*}\right)=\left[\frac{y_{t} u^{\prime \prime}\left(y_{t}\right)}{u^{\prime}\left(y_{t}\right)}\right]^{2} \frac{1}{d t} E_{t}\left(\frac{d y_{t}}{y_{t}}\right)_{c}^{2}-\frac{y_{t} u^{\prime \prime}\left(y_{t}\right)}{u^{\prime}\left(y_{t}\right)} \frac{y_{t}^{*} \bar{u}^{\prime \prime}\left(y_{t}^{*}\right)}{\bar{u}^{\prime}\left(y_{t}^{*}\right)} \frac{1}{d t} E_{t}\left(\frac{d y_{t}}{y_{t}}\right)_{c}\left(\frac{d y_{t}^{*}}{y_{t}^{*}}\right) \\
-\lambda E\left[J_{\varepsilon} \frac{u^{\prime}\left(y_{t}(1+J)\right)-u^{\prime}\left(y_{t}\right)}{u^{\prime}\left(y_{t}\right)}\right]
\end{array}
$$

c) the jump amplitude of the nominal exchange rate is:

$$
J_{e}=\frac{u^{\prime}\left(y_{t}\right)}{u^{\prime}\left(y_{t}(1+J)\right)(1+J)}-1, \quad J_{e}^{*}=\frac{\bar{u}^{\prime}\left(y_{t}^{*}\left(1+J^{*}\right)\right)\left(1+J^{*}\right)}{\bar{u}^{\prime}\left(y_{t}^{*}\right)}-1
$$

d) the nominal expected depreciation is:

$$
\begin{aligned}
\mu_{e}-\left(R_{t}-R_{t}^{*}\right)= & \frac{1}{d t} E_{t}\left\{\left(\frac{d m_{t}}{m_{t}}\right)_{c}+\left[1+\frac{y_{t} u^{\prime \prime}\left(y_{t}\right)}{u^{\prime}\left(y_{t}\right)}\right]\left(\frac{d y_{t}}{y_{t}}\right)_{c}\right\}^{2} \\
& -\left[1+\frac{y_{t} u^{\prime \prime}\left(y_{t}\right)}{u^{\prime}\left(y_{t}\right)}\right]\left[1+\frac{y_{t}^{*} \bar{u}^{\prime \prime}\left(y_{t}^{*}\right)}{\bar{u}^{\prime}\left(y_{t}^{*}\right)}\right] \frac{1}{d t} E_{t}\left(\frac{d y_{t}}{y_{t}}\right)_{c}\left(\frac{d y_{t}^{*}}{y_{t}^{*}}\right) \\
& -\frac{1}{d t} E_{t}\left(\frac{d m_{t}}{m_{t}}\right)_{c}\left(\frac{d m_{t}^{*}}{m_{t}^{*}}\right)-\lambda E\left[J \frac{u^{\prime}\left(y_{t}(1+J)\right)(1+J)-u^{\prime}\left(y_{t}\right)}{u^{\prime}\left(y_{t}\right)}\right]
\end{aligned}
$$

(60) 


\section{Proof:}

By applying the Ito Lemma to the function given by (9) one can obtain:

$$
\begin{aligned}
\frac{d \varepsilon_{t}}{\varepsilon_{t}} & =\frac{y_{t}^{*} \bar{u}^{\prime \prime}\left(y_{t}^{*}\right)}{\bar{u}^{\prime}\left(y_{t}^{*}\right)}\left(\frac{d y_{t}^{*}}{y_{t}^{*}}\right)_{c}-\frac{y_{t} u^{\prime \prime}\left(y_{t}\right)}{u^{\prime}\left(y_{t}\right)}\left(\frac{d y_{t}}{y_{t}}\right)_{c}+\frac{1}{2} \frac{y_{t}^{* 2} \bar{u}^{\prime \prime \prime}\left(y_{t}^{*}\right)}{\bar{u}^{\prime}\left(y_{t}^{*}\right)}\left(\frac{d y_{t}^{*}}{y_{t}^{*}}\right)_{c}^{2} \\
& -\frac{1}{2}\left\{\frac{y_{t}^{2} u^{\prime \prime \prime}\left(y_{t}\right)}{u^{\prime}\left(y_{t}\right)}-2\left[\frac{y_{t} u^{\prime \prime}\left(y_{t}\right)}{u^{\prime}\left(y_{t}\right)}\right]^{2}\right\}\left(\frac{d y_{t}}{y_{t}}\right)_{c}^{2}-\frac{y_{t}^{*} \bar{u}^{\prime \prime}\left(y_{t}^{*}\right)}{\bar{u}^{\prime}\left(y_{t}^{*}\right)} \frac{y_{t} u^{\prime \prime}\left(y_{t}\right)}{u^{\prime}\left(y_{t}\right)}\left(\frac{d y_{t}}{y_{t}}\right)_{c}\left(\frac{d y_{t}^{*}}{y_{t}^{*}}\right)_{c} \\
& +\left[\frac{u^{\prime}\left(y_{t}\right)}{u^{\prime}\left(y_{t}(1+J)\right)}-1\right] d N_{t}+\left[\frac{\bar{u}^{\prime}\left(y_{t}^{*}\left(1+J^{*}\right)\right)}{\bar{u}^{\prime}\left(y_{t}^{*}\right)}-1\right] d N_{t}^{*}
\end{aligned}
$$

Using the conditional expectation operator and the equation for the real interest rate (equation (34)) for the two countries one obtains equation (58).

In order to obtain the expected nominal depreciation one can use the Ito Lemma to the function given by (8) :

$$
\begin{aligned}
\frac{d e_{t}}{e_{t}} & =\left[1+\frac{y_{t}^{*} \bar{u}^{\prime \prime}\left(y_{t}^{*}\right)}{\bar{u}^{\prime}\left(y_{t}^{*}\right)}\right]\left(\frac{d y_{t}^{*}}{y_{t}^{*}}\right)_{c}-\left[1+\frac{y_{t} u^{\prime \prime}\left(y_{t}\right)}{u^{\prime}\left(y_{t}\right)}\right]\left(\frac{d y_{t}}{y_{t}}\right)_{c}+\left(\frac{d m_{t}}{m_{t}}\right)_{c}-\left(\frac{d m_{t}^{*}}{m_{t}^{*}}\right)_{c} \\
& +\frac{1}{2}\left[\frac{y_{t}^{* 2} \bar{u}^{\prime \prime}\left(y_{t}^{*}\right)}{\bar{u}^{\prime}\left(y_{t}^{*}\right)}+2 \frac{y_{t}^{*} \bar{u}^{\prime \prime}\left(y_{t}^{*}\right)}{\bar{u}^{\prime}\left(y_{t}^{*}\right)}\right]\left(\frac{d y_{t}^{*}}{y_{t}^{*}}\right)_{c}^{2} \\
& -\frac{1}{2}\left\{\frac{y_{t}^{2} u^{\prime \prime \prime}\left(y_{t}\right)}{u^{\prime}\left(y_{t}\right)}-2\left[\frac{y_{t} u^{\prime \prime}\left(y_{t}\right)}{u^{\prime}\left(y_{t}\right)}\right]^{2}-2 \frac{y_{t} u^{\prime \prime}\left(y_{t}\right)}{u^{\prime}\left(y_{t}\right)}-2\right\}\left(\frac{d y_{t}}{y_{t}}\right)_{c}^{2} \\
& -\left[1+\frac{y_{t} u^{\prime \prime}\left(y_{t}\right)}{u^{\prime}\left(y_{t}\right)}\right]\left[1+\frac{y_{t}^{*} \bar{u}^{\prime \prime}\left(y_{t}^{*}\right)}{\bar{u}^{\prime}\left(y_{t}^{*}\right)}\right]\left(\frac{d y_{t}}{y_{t}}\right)_{c}\left(\frac{d y_{t}^{*}}{y_{t}^{*}}\right)_{c} \\
& \left.+\left(\frac{d m_{t}^{*}}{m_{t}^{*}}\right)_{c}^{2}-\left(\frac{d m_{t}}{m_{t}}\right)\right)_{c}\left(\frac{d m_{t}^{*}}{m_{t}^{*}}\right)_{c} \\
& -\left[1+\frac{y_{t} u^{\prime \prime}\left(y_{t}\right)}{u^{\prime}\left(y_{t}\right)}\right]\left(\frac{d y_{t}}{y_{t}}\right)_{c}\left(\frac{d m_{t}}{m_{t}}\right)_{c}-\left[1+\frac{y_{t}^{*} \bar{u}^{\prime \prime}\left(y_{t}^{*}\right)}{\bar{u}^{\prime}\left(y_{t}^{*}\right)}\right]\left(\frac{d y_{t}^{*}}{y_{t}^{*}}\right)_{c}\left(\frac{d m_{t}^{*}}{m_{t}^{*}}\right) \\
& +\left[\frac{u^{\prime}\left(y_{t}\right)}{u^{\prime}\left(y_{t}(1+J)\right)(1+J)}-1\right] d N_{t}+\left[\frac{\bar{u}^{\prime}\left(y_{t}^{*}\left(1+J^{*}\right)\right)\left(1+J^{*}\right)}{\bar{u}^{\prime}\left(y_{t}^{*}\right)}-1\right] d N_{t}^{*}
\end{aligned}
$$


The equation (60) can be obtained by applying the conditional expectation operator and the equation for the nominal interest rate for the two countries (equation (35)).

q.e.d.

\section{CONCLUSION}

In this paper we developed a continuous time general equilibrium model for a two country Lucas type economy assuming that the output in the two countries follows a jump-diffusion stochastic process. We obtained results concerning the determination of the interest rate, and of the risk premium in this two-country world, as well as the dynamics equation of the real and of the nominal exchange rates.

The main result of the paper is the expression of the risk premium in this economy. The risk premium theorised by the model consists of two terms: the classical CCAPM term relating the premium to the risk aversion and the covariance between consumption and asset prices, and a term, specific to this model, quantifying the premium required by the investors due to jumps in output.

\section{REFERENCES}

[1] Bailey, W., and R. Stulz, (1989), "The pricing of Stock Index Options in a General Equilibrium Model," Journal of Financial and Quantitative Analysis 24, 1-12.

[2] Bakshi, G., and Z. Chen, (1997), "Equilibrium Valuation of Foreign Exchange Claims," Journal of Finance 52, 799-826.

[3] Bakshi, G. S., and Z. Chen, (1996), "Inflation, Asset Prices, and the Term Structure of Interest Rates in Monetary Economies," The Review of Financial Studies 9, 241-275.

[4] Bjork, T., (1998), Arbitrage Theory in Continuous Time, Oxford University Press.

[5] Breeden, D., (1979), "An Intertemporal Asset Pricing Model With Stochastic Consumption and Investment Opportunities," Journal of Financial Economics 7, 265-296.

[6] Breeden, D., (1986), "Consumption, Production, Inflation and Interest Rates: A Synthesis," Journal of Financial Economics 16, 3-40.

[7] Breeden, D., and R. Litzenberger, (1978), "Price of state contingent claims implicit in option prices," Journal of Business 51, 621-652.

[8] Cont, R., and P. Tankov, (2004), Financial modeling with jump processes, CRC Press.

[9] Cox, J. C., and C. Huang, (1989), "Optional consumption and portfolio policies when assets prices follow a diffusion process," Journal of Economic Theory 49, 33-83.

[10] Cox, J. C., J. E. Ingersoll, and S. A. Ross, (1985), "An Intertemporal General Equilibrium Model of Asset Prices," Econometrica 53, 363-384. 
[11] Detemple, J., and L. Selden, (1991), "A general equilibrium analysis of option and stock market interactions," International Economic Review 32, 279 -303.

[12]Fleming, W., and R. Rishel, (1975), Deterministic and Stochastic Optimal Control, Springer Verlag.

[13] Grossman, S., and R. Shiller, (1982), "Consumption correlatedness and risk measurement in economies with non-traded assets and heterogeneous information," Journal of Financial Economics 10, 195-210.

[14] Jacod, J., and A. N. Shiryaev, (2003), Limit Theorems for Stochastic Processes, 2nd Edition, Springer Verlag.

[15]Lucas, R., (1978), "Asset Prices in an Exchange Economy," Econometrica 46, 1429-1445.

[16] Lucas, R., (1982), "Interest Rates and Currency Prices in a Two-Country World," Econometrica 10, 335-360.

[17] Merton, R. C., (1973), "An Intertemporal Capital Asset Pricing Model," Econometrica 41, 867-887.

[18] Musiela, M., and M. Rutkowski, (1997), Martingale Methods in Financial Modelling, Springer Verlag.

[19] Naik, V., and M. Lee, (1990), "General Equilibrium Pricing of Options on the Market Portfolio with Discontinuous Returns," The Review of Financial Studies 3, 493-521.

[20] Oksendal, B., (2000), Stochastic Differential Equations (5th Edition), Springer Verlag.

[21] Protter, P., (1992), Stochastic Integration and Differential Equations, Springer Verlag.

[22] Revuz, D., and M. Yor, (1991), Continuous Martingales and Brownian Motion, Springer Verlag.

[23] Stapleton, R. C., and M. G. Subrahmanyam, (1978), "A Multiperiod Equilibrium Asset Pricing Model," Econometrica 46, 1077-1096.

[24] Stulz, R. M., (1987), "An Equilibrium Model of Exchange Rate Determination and Asset Pricing with Nontraded Goods and Imperfect Information," The Journal of Political Economy 95, 1024-1040.

[25] Vasicek, O., (1977), "An Equilibrium Characterization of the Term Structure," Journal of Financial Economics 5, 177-188. 